\title{
The Relationship of CT Mean Modulated Dose-Length Product and Body Mass Index During Routine ${ }^{18}$ F- FDG PET/CT Studies
}

\author{
Simon Atkins ${ }^{1,2}$ \\ ${ }^{1}$ The Institute of Nuclear Medicine, University College Hospital London, London, NW1 2BU, UK \\ ${ }^{2}$ Epworth Radiation Oncology, Epworth Healthcare, Richmond, VIC 3121, Australia
}

Email address:

simon.atkins05@gmail.com

To cite this article:

Simon Atkins. The Relationship of CT Mean Modulated Dose-Length Product and Body Mass Index During Routine ${ }^{18}$ F- FDG PET/CT Studies. International Journal of Medical Imaging. Vol. 3, No. 5, 2014, pp. 94-97. doi: 10.11648/j.ijmi.20150305.12

\begin{abstract}
AIM: To determine the relationship of body mass index (BMI) on the mean dose length product (DLP) values acquired using modulated (automatic exposure control) and standard computed tomography (CT) scanning protocols as part of a typical ${ }^{18}$ F-FDG PET/CT study. METHODS: A retrospective study was performed and the dose-length product and BMI values from routine ${ }^{18} \mathrm{~F}$-FDG PET/CT scans of 51 patients were recorded. The scans were performed on a 16-slice PET/CT scanner by using an automatic exposure control (AEC) system. DLP, BMI, age, sex and number of bed positions were documented for each patient. RESULTS: Twenty-four women and 27 men were included in the study (mean age, 52.5 years). The mean BMI was $24.76 \mathrm{~kg} / \mathrm{m}^{2}$. The mean modulated DLP was $528.25 \mathrm{mGy} / \mathrm{cm}$. Patients were grouped according to BMI (normal: BMI $<25$, overweight: BMI $25-30$, obese: BMI $>30$ ) and age ( $\leq 18$ years, $19-59$ years, $\geq 60$ years). The mean modulated DLP decreased by $22.77 \%$ for patients in the normal BMI group $(\mathrm{P}<0.001)$. The obese group of patient's mean modulated DLP was $26.29 \%$ higher $(\mathrm{P}<0.01)$. The DLP decreased by $22.43 \%$ for patients aged 60 years and above compared with patients in the $19-59$ age group. CONCLUSION: The use of modulated scanning protocol significantly reduces the integrated dose received from a whole body CT scan for patients with a BMI $<25$. Increasing patient size $(\mathrm{BMI}>25)$ significantly increases the integrated dose received. The possible change in body composition with age may also indicate a reduction in dose received from a whole body $\mathrm{CT}$ scan using AEC.
\end{abstract}

Keywords: Dose-Length Product, Body Mass Index, Automatic Exposure Control

\section{Introduction}

The use of ionising radiation in medical imaging is governed by the ALARA principle. Thus, clinically acceptable image quality should be obtained at a dose that is 'as low as reasonably achievable' [1]. CT accounts for approximately $12 \%$ of the $\mathrm{x}$-ray based examinations carried out in the England [2], however it contributes more than 50\% of the combined radiation dose to the population [3, 4].

The study by Gonzalez and Darby [5] estimated the increased risk of cancer development from diagnostic x-ray procedures is between 0.6 and $3.2 \%$. Therefore, it is incumbent that low-dose CT imaging protocols are developed to ensure that patients can receive significant medical benefits whilst minimising the risks associated with ionising radiation. The CT scanning protocol chosen for each patient at this institution was previously based on the patient's Body Mass
Index (BMI) [6]. A fixed $\mathrm{kVp}$ value of 140 was used and a tube current $(\mathrm{mA})$ of 80,100 , or 120 was chosen depending on the BMI of the patient. It was proposed that a dose modulated method should be implemented utilising $120 \mathrm{kVp}$ and a modulated $m A$, individually tailored to the BMI of each patient. The aim of dose modulation is to achieve a standard level of noise throughout an image, and maximise the image quality for a given dose. In contrast to the fixed $\mathrm{mA}$ method used previously, the modulated protocol would now increase $\mathrm{mA}$ in anatomical regions of high attenuation, and decrease $\mathrm{mA}$ in regions of low attenuation. Dose varies proportionally as $\mathrm{kV}^{2}$, thus a small reduction in $\mathrm{kVp}$ leads to a large reduction in dose. A scanning value of $140 \mathrm{kVp}$ is rarely used in a radiology setting with diagnostic $\mathrm{CT}$ scans typically being carried out at $120 \mathrm{kVp}$. The reason for its use has been purely traditional, based on the need for early scanners to have X-ray energies with similar scattering properties to those available in 
PET. However the necessary corrections have now been derived at $120 \mathrm{kVp}$, thus the motivation to standardise.

The new dose modulated protocol was devised using an anthropomorphic phantom (Rando, The Phantom Laboratory, New York, USA). The phantom was then scanned using the standard protocol (Rando is based on a $70 \mathrm{~kg}$ standard man, thus a current of $80 \mathrm{~mA}$ was used). The magnitude of $\mathrm{kVp}$ was then decreased to 120 , and the noise index changed until the dose length product (DLP) from the new protocol was the same as the standard protocol $\mathrm{mA}$. The DLP unique to the patient is displayed at the cessation of a CT scan. The DLP $(\mathrm{mGy} / \mathrm{cm})$ is indicative of the total deposited energy, and is defined as the length of examination (in the $\mathrm{z}$ direction) multiplied by the CT dose index (CTDI) [7].

The purpose of this study was to determine the relationship of body mass index (BMI) on the mean dose length product (DLP) values acquired from a routine CT scan with a 16-slice MDCT scanner using an AEC system.

\section{Patients and Methods}

This was a retrospective study in which 53 patients were imaged using a whole body CT scan as part of their scheduled Fluorine-18 Fluorodeoxyglucose (F-18 FDG) PET/CT study. All patients had their weight and height measured before the study. Body mass index (BMI) $\left(\mathrm{kg} / \mathrm{m}^{2}\right)$ was calculated for each patient using their weight $(\mathrm{kg})$ and height $(\mathrm{m})$. The PET/CT studies were performed using a 16-slice MDCT scanner (Discovery ST; GE Healthcare, Little Chalfont, UK). A dose modulated CT scanning protocol was used (Table 1).

The tube current was controlled by the manufacturer's software package Smart mA (GE Healthcare) [8]. This AEC system uses the patient's scout image information (patient density, size and shape) to modulate the tube current within different anatomic regions (z-axis modulation) and angular sections ( $\mathrm{x} / \mathrm{y}$ modulation). Smart $\mathrm{mA}$ determines the appropriate tube current level (mAs) for each section of the patient to maintain a comparable image quality throughout the scan length. The software package generates a unique dose-length product (DLP) (mGy.cm) for each patient study.

The $\mathrm{CTDI}_{\mathrm{vol}}$ quantifier is the $\mathrm{CTDI}_{\mathrm{w}}$ for each study corrected for couch pitch. The DLP is an indicator of the integrated radiation dose for the whole series of images and is measured in $\mathrm{mGy} / \mathrm{cm}[9,10]$.

$$
\mathrm{DLP}=\mathrm{CTDI}_{\mathrm{vol}} * \text { length of the irradiated region }
$$

A PET scan is acquired as a series of several distinct bed motions, called bed positions. For each patient the dose length product (DLP) values were recorded and standardised to 6 bed positions. One bed position is equivalent to $15.2 \mathrm{~cm}$ in length. This standardisation accounted for differences in the physical length of each study ( $\mathrm{z}$ direction) due to the variations in patient height. The DLP values were standardised using the following:

$$
\mathrm{DLP}_{\text {standardised }}=\mathrm{DLP} \times(6 / \text { number of bed positions })
$$

From the CT studies the patients were categorised by BMI (normal: $<25 \mathrm{~kg} / \mathrm{m}^{2}$, overweight: $25-30 \mathrm{~kg} / \mathrm{m}^{2}$, obese: $>30$ $\mathrm{kg} / \mathrm{m}^{2}$ ) and age group (group 1: $=<18$ years, group 2: $19-59$ years, group $3:>=60$ years). BMI and DLP were further analysed based on patient age. Statistical analysis was performed with commercially available statistical software (SPSS for Windows, version 14.0. Chicago, SPSS Inc). The Student $t$ test (one-sided) was used to compare the modulated and static DLP values measured for each BMI subgroup. A $P$ value of less than .05 was used to indicate a statistically significant difference.

Table 1. Standard and modulated imaging protocols for the computed tomography sequence of the whole body PET/CT study.

\begin{tabular}{lllllll}
\hline CT Protocol & $\mathbf{k V p}$ & $\mathbf{m A}$ & Rotation $\mathbf{( s )}$ & Pitch & Slice thickness (mm) & Slice separation (mm) \\
\hline Standard & 140 & $80,100,120$ & 0.8 & 1.750 & 2.5 & 2.5 \\
Modulated & 120 & $10-300$ & 0.8 & 1.375 & 2.5 & 2.0 \\
\hline
\end{tabular}

\section{Results}

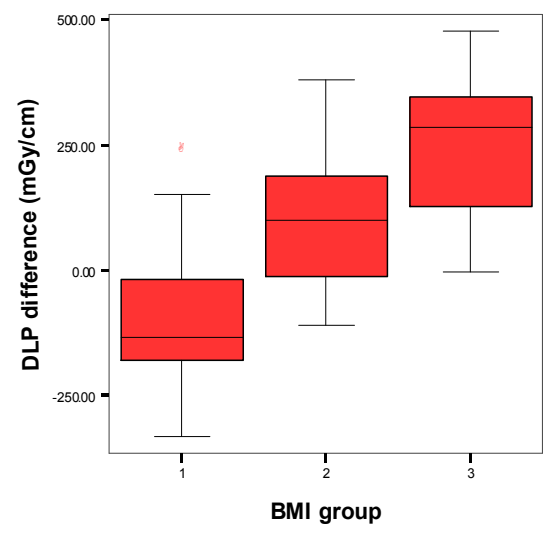

Figure 1. Boxplot of BMI group (Group 1, normal: BMI <25; Group 2, overweight: BMI 25 - 30; Group 3, obese: BMI >30) vs DLP difference between the standard and modulated scanning protocols $(\mathrm{mGy} / \mathrm{cm})$.
Twenty-four women and 27 men $(n=53)$ were included in the study. Their ages ranged from 9 - 79 years (mean age, 52.5 years). The BMI ranged from $14.79-34.52 \mathrm{~kg} / \mathrm{m}^{2}$ (mean [SD], $\left.24.8[ \pm 4.6] \mathrm{kg} / \mathrm{m}^{2}\right)$. The modulated DLP ranged from $77.8-$ $1202.8 \mathrm{~m}^{2}$ (mean [SD], $\left.528.2[ \pm 279.4] \mathrm{mGy} / \mathrm{cm}\right)$. The null hypothesis was that the mean DLP values are the same for both standard and modulated CT protocols.

\subsection{Body Mass Index}

Patients were grouped by BMI and analysed statistically using Students one-sided $\mathrm{t}$ test. The Boxplot in Figure 1 displays the difference between the DLP values measured using the modulated protocol and the DLP values expected had the patients been scanned using the standard protocol. Figure 2 shows a comparison of standardised DLP to BMI showed that DLP increased with increasing BMI. The 
comparison of means between the modulated and standard DLP values is summarised in Table 2.

Patients in the normal group $(\mathrm{BMI}<25)$ demonstrated a highly significant outcome $(\mathrm{t}=-3.74, \mathrm{df}=26, \mathrm{P}=0.001)$. The mean modulated DLP decreased by $22.77 \%(\mathrm{P}<0.001)$. Patients in the overweight group (BMI 25 - 30) demonstrated a significant outcome whereby the DLP increased by $15.13 \%$ with increasing $\mathrm{BMI}(\mathrm{t}=2.549, \mathrm{df}=15, \mathrm{P}=0.022)$. Patients in the obese group (BMI > 30) demonstrated a strongly significant outcome in comparison to the standard CT protocol $(\mathrm{t}=4.116, \mathrm{df}=8, \mathrm{P}=0.003)$. The mean modulated DLP for this group of patient's increased by $26.29 \%(\mathrm{P}<0.01)$.

\subsection{Age Group}

When comparing the mean DLP by age group, age group 1 and age group 3 had significantly and marginally lower DLP values respectively when compared with patients in group 2 . The results are displayed in table 3 . The DLP decreased by $22.43 \%$ for patients aged 60 and above compared with patients in the $19-59$ age group.

The clinical details for the two paediatric cases imaged are displayed in table 4. Current practise for young (paediatric/adolescent) patients is to deliver an average DLP = $212.62 \mathrm{mGy} / \mathrm{cm}$ per scan $(\mathrm{kVp}=140, \mathrm{~mA}=40)$. This is only an average value; the $\mathrm{mA}$ is actually modified on a patient by patient basis, depending on the size of the patient. The modulated CT protocol delivered a reduction in DLP to patient 1 and an increase in DLP to patient 2.

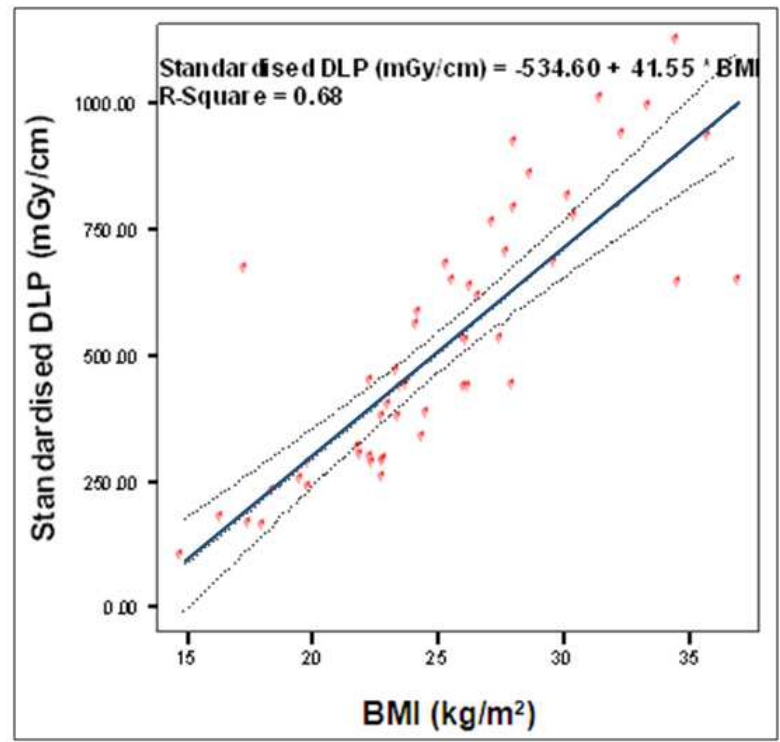

Figure 2. Graph showing correlation between Body Mass Index (BMI) vs Standardised Dose Length Product (DLP) for patients undergoing CT scans using the modulated scanning protocol. The blue line indicates the regression line fit; the equation of the fit is: Standardised $D L P(m G y / c m)=-534.60+$ $41.55 * B M I$.

Table 2. Standard and modulated CT protocols DLP comparison. The mean DLP difference (\%) represents the percentage change in dose between the two protocols.

\begin{tabular}{llll}
\hline BMI & DLP Standard CT protocol $(\mathbf{m G y} / \mathbf{c m})$ & DLP Modulated CT protocol (mGy/cm) & Mean DLP difference (\%) \\
\hline Normal $(\mathrm{n}=27)$ & 425.25 & $328.43 \pm 134.51$ & $-22.77 * * *$ \\
Overweight $(\mathrm{n}=16)$ & 531.56 & $626.35 \pm 148.76$ & $+15.13^{*}$ \\
Obese $(\mathrm{n}=9)$ & 637.88 & $865.47 \pm 165.88$ & $+26.29 * *$ \\
\hline
\end{tabular}

Specific levels of significance: $\mathrm{P}<0.05(*), \mathrm{P}<0.01(* *)$ and $\mathrm{P}<0.001(* * *)$.

Table 3. Mean modulated DLP values categorised by age.

\begin{tabular}{llll}
\hline Group & Sex & Age range & DLP Modulated CT protocol (mGy/cm) \\
\hline $1(\mathrm{n}=2)$ & Male $=1$, Female $=1$ & $\leq 18$ years & $183.04 \pm 126.80$ \\
$2(\mathrm{n}=29)$ & Male $=13$, Female $=16$ & $19-59$ years & $567.86 \pm 239.97$ \\
$3(\mathrm{n}=20)$ & Male $=10$, Female $=10$ & $\geq 60$ years & $463.83 \pm 253.76$ \\
\hline
\end{tabular}

Table 4. Modulated DLP values for paediatric cases.

\begin{tabular}{lllllll}
\hline & Age (years) & Height $(\mathbf{m})$ & Weight $(\mathbf{k g})$ & BMI & DLP (mGy/cm) & Mean DLP difference (\%) \\
\hline Patient 1 & 9 & 1.30 & 25 & 14.79 & 93.37 & -56.09 \\
Patient 2 & 11 & 1.58 & 56 & 22.43 & 272.70 & +28.26 \\
\hline
\end{tabular}

\section{Discussion}

The mean DLP measured for patients with a BMI $<25$ (normal) showed a significant dose reduction using the modulated CT protocol. A total of 6 patients (normal group sample size $=27$ ) were delivered dose values above the standard CT protocol value of $425.25 \mathrm{mGy} / \mathrm{cm}$.

Overall, $68 \%(17 / 25)$ of patients belonging to the overweight and obese groups measured DLP values above the standard CT protocol values (BMI specific). This increase in
DLP using the modulated CT protocol is most possibly attributed to the increase the photon flux (variable $\mathrm{mA}$ ) in areas of high attenuation and noise standardisation. The relationships between obesity and increasing DLP from CT scanning protocols have been published previously $[11,12$, 13]. An increase in DLP has been shown to directly relate to the increased risk of cancer induction and heritable disease $[1]$.

Therefore, as obesity rates continue to rise [14], this increase in radiation dose presents a potential rise in the risk of stochastic effects. Radiation dose reduction is always 
desirable, especially so in children and adolescents. From the young patients scanned a large reduction in DLP was seen in one patient and an increase in the other. From this group it should be noted that by analysing BMI by age and sex, patient 1 was on the underweight side of normal, and patient 2 was on the overweight side of normal. Patients in age group 3 (> $>0$ years) displayed a lower mean DLP when compared to the age group 2. Age group 3 measured a mean BMI $=23.98 \mathrm{~kg} / \mathrm{m}^{2}$ and group $2 \mathrm{BMI}=26.40 \mathrm{~kg} / \mathrm{m}^{2}$, therefore explaining the reduction in DLP. This BMI difference in the older age group may also reflect a change in body composition with age.

\section{Conclusion}

These preliminary results show that the modulated CT protocol delivers a significant reduction in dose (standardised DLP) to patients with a BMI $<25 \mathrm{~kg} / \mathrm{m}^{2}$. Overweight and obese patients experienced a $15 \%-26 \%$ increase in the measured DLP per CT study. The increase in DLP delivered to patients with a $\mathrm{BMI}>25$ using the modulated $\mathrm{CT}$ protocol suggests that the current standard protocol maybe be qualitatively inferior (suboptimal image quality), as it does not allow for regions of high attenuation, rather it uses a fixed $m A$ for each patient. However, further qualitative analysis must be carried out before a conclusion on image quality can be made.

\section{References}

[1] ICRP, ICRP Publication 103, "Recommendations of the International Commission on Radiological Protection", Amsterdam (NLD), Elsevier, 2007.

[2] NHS England Analytical Services (Operations) 2014, NHS Imaging and Radiodiagnostic activity (2013/14), NHS England, Available from: $<$ http://www.england.nhs.uk/statistics/wp-content/uploads/site s/2/2013/04/KH12-release-2013-14.pdf >. [11 October 2014].

[3] P.C. Shrimpton, M.C. Hillier, M.A. Lewis and M. Dunn, "National Survey of Doses from CT in the UK: 2003," British Journal of Radiology, Vol. 79, Issue. 948, pp. 968-980, April 2006.

[4] P.D. Deak, O. Langner, M. Lell and W. Kalender, "Effects of Adaptive Section Collimation on Patient Radiation Dose in
Multisection Spiral CT," Radiology, Vol. 252: No. 1, pp. 140-147, July 2009.

[5] A.B Gonzalez and S. Darby, "Risk of cancer from diagnostic x-rays: estimates for the UK and 14 other countries," Lancet, Vol. 363, Issue. 9406, pp. 345-51, January 2004.

[6] World Health Organisation, Global Database on Body Mass Index 2014, Available from: < http://www.who.int/en/>. [March 2014].

[7] M. Lewis, "ImpactScan course notes: Principles of CT Dosimetry 2002," Available from: $<$ http://www.impactscan.org/slides/impactday/ctdosimetry/sld 014.htm>, [March 2014]

[8] GE Healthcare, "A Guide to CT Radiation Dose Management 2012," Available from: <http://www.gehealthcare.com>, [March 2014].

[9] W. Huda, K. M. Ogden and M. R. Khorasani, "Converting Dose-Length Product to Effective Dose at CT," Radiology, Vol. 248: No.3, pp.995-1003, September 2008.

[10] D. Platten, "ImpactScan course notes: Multi-slice helical CT physics and technology," Available from: $<$ http://www.impactscan.org/slides/eanm2002/sld001.htm>, [March 2014].

[11] Manowitz A, Sedlar M, Griffon M, Miller A, Miller J, Markowitz S. "Use of BMI guidelines and individual dose tracking to minimize radiation exposure from low-dose helical chest CT scanning in a lung cancer screening program," Academic radiology, Vol 19, Issue 1, pp. 84-8, January 2012.

[12] Chan V.O, McDermott S, Buckley O, Allen S, Casey M, O'Laoide R and Torreggiani W.C. "The relationship of body mass index and abdominal fat on the radiation dose received during routine computed tomographic imaging of the abdomen and pelvis," Canadian Association of Radiologists Journal, Vol. 63, Issue 4, pp. 260-266, November 2012.

[13] Odedra D, Blobel J, AlHumayyd S, Durand M, Jimenez-Juan L, Paul N. "Image noise-based dose adaptation in dynamic volume CT of the heart: dose and image quality optimisation in comparison with BMI-based dose adaptation," European radiology, Vol. 24, Issue 1, pp. 86-94, January 2014.

[14] World Health Organisation (WHO), Technical Report Series 894, 'Obesity: Preventing and Managing the Global Epidemic," WHO, Singapore, 2000. 